\title{
Rethinking primary health care ethics: ethics in contemporary primary health care in the United Kingdom
}

Robyn Martin CRIPACC, Faculty of Health and Human Sciences, University of Hertfordshire, UK

\begin{abstract}
Ethics have long been recognized as underpinning primary health care. While discrete understandings of ethics have developed to support many areas of health care and research, there has been little attempt to formulate an ethics framework which is focused on primary health care. Developments both within and external to primary health care practice make it timely to address primary health care ethics; in particular, government initiatives contained in Shifting the Balance of Power, the increasing emphasis on evidence based practice, and the greater recognition of patient rights within English law resulting from the Human Rights Act 1998. A starting point to formulating an ethics framework would be to define the domain of primary health care. We can then identify those areas particular to primary health care which raise issues of conflict and change and which would benefit from ethics guidance.
\end{abstract}

Key words: autonomy; consent; ethics; evidence based practice; human rights; primary health care; professional boundaries

\section{Introduction}

The importance of an ethical framework to health practice cannot be disputed. Analysis and debate on the nature and content of that ethical framework has become increasingly sophisticated, and discrete understandings of ethics have emerged appropriate to different types of health practice. We now have codes of research ethics, bioethics, public policy ethics and public health ethics, while medical ethics tends to focus on interventionist or traumatic clinical care. Ethics have long been recognized in the context of primary health care, but have been seen as part of an academic discipline in which experts deliberate good and bad, right and wrong, in order to solve complex moral questions. In fact ethics pervade the smallest and simplest health issue, and serve to provide a framework for everyday practice.

Can we identify a body of ethics theory with particular legitimacy for primary care? Does

Address for correspondence: Robyn Martin, CRIPACC, Faculty of Health and Human Sciences, University of Hertfordshire, College Lane, Hatfield, AL10 9AB, UK. E-Mail: r.m.martin@herts.ac.uk primary care practice give rise to any issues of particular ethical complexity? Three recent developments make it timely for fresh consideration of the role of ethics in primary care. Government initiatives reflected in Shifting the Balance of Power (Department of Health, 2001a) have resulted in changes to the philosophy, content, priorities and mode of provision of primary care. Additionally there have been two external developments which will constrain primary health care practice: the introduction and increasing dominance of evidence based medicine, and the passing of the Human Rights Act 1998 which introduces into English domestic law the European Convention on Human Rights and Fundamental Freedoms, and recognizes new rights and responsibilities within health care.

However, before we can consider the content of primary care ethics, we will need to define what we mean by primary care. This is not just a question of semantics. Ethics do not operate in a vacuum, but serve to help with problem solving and decision making in hard cases. Hard cases are more likely to arise where there is change and uncertainty. An understanding of the boundaries 
and responsibilities of primary care practice will be essential for exploring ethics in primary care.

\section{Primary (health) care?}

There has never been an accepted or consistent definition of 'primary care' within the United Kingdom. The term has been used to convey the essence of personal, intimate, holistic and caring health provision; here 'primary' represents a value in, or philosophy of, health provision. It has been used to suggest the hierarchical status of health care; here primary applies to both the level of care - initial, basic care, and the mode of delivery of care - first point of entry into the health system. It has been used to describe a strategy of health care provision in which 'primary' refers to the type of care provider - generalist doctors and nurses, and the type of recipient - care for all in accordance with basic principles of social justice. The World Health Organization has meanwhile preferred the alternative term 'primary health care', where 'primary' describes health rather than care; primary health care suggests responsibility for everyday, continuing, general health concerns.

A new approach to primary care within the UK was introduced with the White Paper, The New NHS: modern, dependable (Department of Health, 1997), reflecting the approach of the 'New Labour' government to health, and in particular to health inequalities. The paper signalled an end to the internal market and introduced policy leading to the establishment of primary care trusts with responsibility for primary and community health services. The importance of primary care services was consolidated in the new millennium with a stream of government papers around the theme 'Shifting the balance of power' (for example, Department of Health, 2001a; 2001b; 2001c; 2002a; 2002b) which gave primary care new meaning, new philosophical underpinning and new responsibilities. The shift in balance of power has not only been that from secondary to primary care, but also a shift in the power relationship between provider and patient (Department of Health, 2001d).

It is still, however, difficult to determine from government literature what exactly is meant by the term 'primary care'. The two principle pieces of legislation regulating health provision in England, the National Health Service Act 1977 and the National Health Service and Community Care Act 1990, make no mention of 'primary care' although they recognize community care, clinical care and public health as identifiable types of healthcare provision. The first legislative reference to primary care comes in the National Health Service (Primary Care) Act 1997 but 'primary care' is not defined in the Act. The Health Act 1999, which formally introduces primary care trusts with responsibility for the exercise of primary care functions, does not specify these functions. One glossary (Department of Health, 2001b) defines primary care as 'The part of the NHS where GPs, community nurses and other clinicians work to provide a first point of contact for patients'. Primary care groups are defined as 'Family doctors, primary care teams and community nurses working together to improve the health of local people. They develop primary care and arrange hospital and community service for their patients...'. Meanwhile secondary care is defined as 'Local Services of a more specialist nature usually provided within acute hospital settings'.

For the purpose of this exploration of primary care ethics a more precise understanding of what is, and what is not, primary care will be necessary. One way of addressing this is to examine the language of official documents and legal instruments regulating current primary care practice. From these the following characteristics of primary care can be identified:

\section{1) Nature of service provider}

- Provided by GPs (family doctors), community nurses and other clinicians (these clinicians being part of a primary care team) (Department of Health, 2001b);

- Requiring a rich mix of differently skilled professionals (Department of Health, 2001c);

- Working across established organisational and professional boundaries (Department of Health, 1997);

- Primary care professionals (Reeves, 2001);

- Social care workers (Milburn, 2002);

- Representatives of patients and the community (Milburn, 2002); 
- The doctor who specializes in the patient (RCGP, 2003);

- Subject to scrutiny (Department of Health, 2003c).

2) Nature of service participant

- Provided for the local people (Department of Health, 2001b);

- With patient and carer information and involvement (Dorrell, 1996) Health and Social Care Act (2001);

- Smaller geographical populations with closer community links (Milburn, 2002);

- Care for patients, families and the community (RCGP, 2003);

- The informed patient (Department of Health, 2001c)

- Patient access to training to allow them to participate fully (Department of Health, 2003b);

- Stakeholders to include patients (Department of Health, 2003c);

- Patient entitlement to information (Department of Health, 2002e);

- Patient entitlement to choice (Department of Health, 2002e).

3) Nature and content of care

- The physical, psychological and social aspects of diagnosis (RCGP, 2003);

- The personal, primary and continuing nature of the care of individuals and families (RCGP, 2003);

- A joined up and holistic approach to patient care (Department of Health, 2002c);

- Patient centred (Department of Health, 2002d);

- Responsible for routine and minor ailments (Department of Health, 2001c), for improving health (Department of Health, 2001b), for promoting health (Department of Health, 2002b), for population screening programmes (Milburn, 2002), for reducing health inequalities (Department of Health, 2002b) and for promoting healthy lifestyles (Department of Health, 2002b);

- To include community mental health services (Department of Health, 2001c);

- To include specialist services in coronary heart disease (Department of Health, 2002c; 2003a), stroke care (Department of Health, 2003a), cancer care (Department of
Health, 2002c; 2003a), smoking cessation(Department of Health, 2003a), palliative care (Department of Health, 2003a), diabetes (Department of Health, 2002c; 2003a), tissue viability (Department of Health, 2003a), colorectal services (Department of Health, 2003a), IV therapy (Department of Health, 2003a), epilepsy services (Department of Health, 2003a), older people (Department of Health, 2002c; 2003a), pain management (Department of Health, 2003a), and children's continence (Department of Health, 2003a);

- To provide services in sexual health (Department of Health, 2003a), respiratory disease (Department of Health, 2003a), dermatology (Department of Health, 2003a), falls prevention (Department of Health, 2003a), chronic illness (Department of Health, 2003a) diet, weight reduction and exercise (Department of Health, 2002b), ophthalmology (Reeves, 2001), trauma and orthopaedics (Reeves, 2001);

- To provide secondary services in the community (outpatients) (Department of Health, 2003a);

- To provide community care on an outreach basis (Department of Health, 2003a).

4) Place of delivery

- Not provided within acute hospital settings (Department of Health, 2001b);

- Helping people stay at home and out of hospital (Department of Health, 2001c);

- As close to home as possible (Department of Health, 2003a);

- 'In the familiar surroundings of their own home and community' (Department of Health, 2003a);

- Working with commerce - surgeries in supermarkets (Secretary of State, 1996).

5) Place in the scheme of health service delivery

- Provided at first point of contact (Department of Health, 2001b);

- The early diagnosis, initial decisions and continuing management of problems (RCGP, 2003);

- Controlling health care locally (Milburn, 2002);

- A gateway to secondary care (Department of Health, 2001c); 
- But not severable from or independent of secondary care (NHS (Primary Care) Act 1997);

- Supporting initiatives led by non health organizations (2002b);

- More care in the community (Department of Health, 2003a), community development and outreach services (Department of Health, 2002b);

- Working with neighbourhood renewal programmes (Department of Health, 2002b);

- Increasing the range of secondary care provided in the community (Department of Health, 2003a);

- Providing an interface with secondary care and hospitals (Department of Health, 2003a);

- Reducing hospital admission (Department of Health, 2003a);

- Developing intermediate care services (rapid response or rehabilitation teams working in community settings) (Reeves, 2001);

- Bringing more resources to the front line (Milburn, 2002).

6) Level of provision

- Not 'more specialist' (which is the province of secondary care) (Department of Health, 2001b);

- But to include 'practitioners who can take on specialist roles' (Department of Health, 2003a);

- 'Highly skilled within their generalist domain' (Department of Health, 2003a).

\section{7) Mode of delivery of provision}

- A convenient, flexible and quick service (Department of Health, 2001c);

- Less time to wait for secondary care (Department of Health, 2003a);

- Extended weekend, evening or open access surgeries (Reeves, 2001);

- NHS walk-in centres (Milburn, 2002);

- Local NHS Direct services (Milburn, 2002);

- Patient transport services (Milburn, 2002).

So we can say of contemporary primary care within the UK that it is administered by a range of service providers with varying degrees of specialist training; it provides services for individuals and community populations; it includes a range of generalist and specialist, chronic and acute services; it takes place primarily but not necessarily in GP practices; it is the first point of contact but may include some secondary services; and it has as a priority speed of service and flexibility of access. It provides continuity of care, holistic care and values the personal relationship between provider and patient, but might also take the form of a one-off, anonymous encounter in an open access environment. The service will generally be limited to persons on the patient list, giving providers some control over distribution of resources, but may also provide unfiltered services (Pringle, 1997). Primary care may soon be provided by private companies which contract to provide healthcare services to local communities (Sunday Times 21 December 2003).

We can also identify some characteristics which do not pertain to primary care. Primary care does not include acute medical treatment (skilled surgery under anaesthesia, resuscitation). Nor does it include treatments which require a high level of specialism (such as administration of chemotherapy). Primary care does not deal with patients with traumatic injury, nor with treatments requiring sophisticated and expensive medical technology.

All of this suggests that the thrust of primary care is no longer who works in primary care, nor the level of care within the hierarchy of care provision, nor even the locus of provision. Rather primary care can now be said to reflect the ideology of continuous, holistic and accessible care, with responsibility for every day, nontraumatic health concerns and health maintenance.

The primary care provider then is more than a person who provides first instance scientific medical expertise to clients. There is a quasi-religious element to primary care provision, in which the provider acts as supporter and advisor in relation to medical, health and social problems. The primary care provider also serves as patient advocate in access to more scientific and technological specialist secondary care medical services, as well as to specialized social services. Who, how and where this service is provided has become less relevant than the quality of the service - personal and supportive, and the focus of the service - on the wider patient health rather than on trauma and disease. If this is so, then 'primary' applies more to 'health' than to 'care'. Contemporary 
practice within the United Kingdom would be more accurately reflected by the term 'primary health care' in line with WHO terminology.

\section{Evidence-based medicine and evidence- based practice}

A second major influence on changes in approach to health services that will have implications for ethics has been the global recognition that all health practice should operate in accordance with the principles of evidence-based medicine. EBM proposes that clinical practice should be based on ' $(t)$ he conscientious, explicit and judicious use of current best evidence in making decisions about individual patients' (Sackett et al., 1996, 2000). Best evidence in this context means scientific best evidence, evidence resulting 'from RCTs (including systematic reviews) and meta-analyses of RCTs' (Sehon and Stanley, 2003), combined with 'the proficiency and judgment that individual clinicians acquire through clinical experience and clinical practice (Sackett et al., 1996). This is not to say that best evidence is perfect evidence. As Goodman notes (Goodman, 2003:15), 'Evidence-based medicine, evidence-based nursing, evidence-based public health, evidence-based psychology - all the sciences that have come to rely on the research-literature nexus must be quite clear about the fallibility and uncertainty of their enterprises.'

The tension between the desire for certainty, (and indeed the promotion of evidence-based medicine as the next best thing to certainty) on the one hand, and the appropriateness of application of EBM to individual clinical treatment on the other, will give rise to 'hard cases' for which we will need ethics guidance. The Oxford Centre for Evidence-based Medicine reminds us on its website (www.cebm.net) that,

External clinical evidence can inform, but never replace, individual clinical expertise that decides whether the external evidence applies to the individual patient at all, and if so, how it should be integrated into a clinical decision. Similarly any external guideline must be integrated with individual clinical expertise in deciding whether and how it matches the patient's clinical state, predicament, and preferences ...
It is in the area of primary health care that EBM may prove most problematic. EBM most frequently reflects the quantitative approach of science rather than qualitative research more common within the social sciences (Malterud, 2001). This prioritization of science favours the (assumed) objectivity, neutrality and accuracy of scientific research over experience, intuition, observation and empathy in the treatment of patients (Loughlin 2003). Yet Davis (1997) has observed that contemporary primary health care means,

that we change from a focus on curative care requiring a high degree of technical skill, specialization grounded in scientific knowledge, and empirical knowledge, to a new focus on simple basic care which aims to maintain life and prevent illness from worsening. It is not a focus on what is sick and not properly functioning, rather PHC focuses on health and health maintenance. In PHC, care action cannot be dissociated from social actions.

Evidence-based practice has 'proved inadequate' (Greenhalgh et al., 2003) and makes 'false and dangerous promises' (Hammersley, 2001) for health education research and appears insufficient for effective health promotion (Tang et al., 2003). Nor is it always a useful tool in diagnosis where personal experience and pattern recognition play and important role (Grahame-Smith, 1995). Much traditional or alternative medicine falls outside the biomedical focus of evidence-based medicine, and it has been argued that the ethos of traditional medicine such as Chinese medicine is incompatible with the ethos of science (Quah, 2003). Yet patients are increasingly demanding access to alternative treatments for chronic illness as well as for illnesses with a possible psychological or social causal component, and these are the types of illness which fall squarely within primary health care.

The report of the Commission on the Future of Health Care in Canada (2002) noted, 'some aspects of primary care approaches are not necessarily grounded in research and evidence, but rather appear to be based on good ideas or preferences'. The WHO Report on Primary Health Care 2003 recognizes the value of evidence-based 
medicine in those areas where the traditional distinctions between specialist care and primary health care are blurred, but also advocates policy development and innovation in the delivery of primary health care services, where it is more difficult to build a coherent base of evidence. The push for scientific evidence-based practice on the one hand, and recognition of the personal dimension of good primary health care on the other, will inevitably create tensions within primary health care practice. We will need ethics to help resolve those tensions.

\section{Human rights and primary health care}

A further influence on contemporary primary health care is recognition that health care must be administered within a framework of human rights not only as a matter of ethics but now in the UK, as a matter of law. The Human Rights Act 1998 provides remedies where a public body such as a primary care trust has breached a right enshrined in the European Convention for the Protection of Human Rights and Fundamental Freedoms. Many of these rights have implications for health, and the Act will assist patients whose rights have been breached to seek judicial review of a treatment decision or policy, or sue for damages where harm results from a breach.

Much attention has been directed to the implications of human rights arguments for the sharp end of medical practice, in particular end-of-life decisions. The Act will however also have implications for primary care provision. This will be the case particularly around patient participation and user involvement, issues which underpin contemporary primary health care. The Human Rights Act has raised awareness of rights, reinforcing expectations of service choice. Patients who have become knowledgeable or even expert on their medical condition may demand treatments and medicines which the provider does not wish to offer. Government policy now emphasizes patient participation in the determination of treatment as essential to the provision of an accountable service. Where treatments or medicines might be beneficial in saving or prolonging life or in preventing pain, patients could use human rights arguments to enforce their demands.
This may not of course be what the government intended by its 'genuine partners' rhetoric, any more than it intended that patients be accorded enforceable rights by the now abandoned Patient's Charter (Department of Health, 1996). However, language serves not only a positivist but also a normative role, and just as patients imbibed the rights culture of the charter in their adversarial approach to failure to meet its standards, so too will patients take on board the language of partnership. Patients as users may demand to be heard not just on issues of system provision (which was probably the original intention of the user involvement policy) but also on issues of individual service provision. Relationships with patients in the primary health care sector will need to be underpinned by true patient autonomy. If primary care providers do not develop strategies for achieving effective user involvement then interactions with patients will be 'conflict-ridden' (Brooks, 2001), and conflict inevitably leads to litigation.

This will impact more on primary health care than on secondary care. Seriously ill patients within the secondary sector will not generally be in a position to make demands or exercise wide choice in respect of treatments. One consequence of the Human Rights Act will be the need to rethink our approaches to patient autonomy in relation to primary care treatment, and it may well be that primary care ethics will need to place greater emphasis on autonomy than is the case in ethics governing other sectors of care.

\section{Ethics in primary health care}

Primary health care has rarely traditionally required practitioners to make front line ethics decisions. Primary health care practice has always operated in a context in which secondary services provide back-up support in hard cases. This is still to some extent the case, but there is no doubt that ethics pervade contemporary primary health care practice. The primary health care provider must liaise with patients, make treatment decisions and process patient information, all of which have an ethics dimension. There are, however, some aspects of contemporary primary health care which raise new ethics concerns, and 
make clear the need for an ethical framework to primary health care.

Ethics are especially important where changes to structures and priorities create an environment of uncertainty. Recent changes in primary health care have led to an 'attitudinal shift' (Brooks, 2001) both within the health service and between service providers and users. New government policy, human rights legislation and the increasing dominance of evidence-based practice magnify that uncertainty, and practitioners can find themselves pressed to make decisions where there is no obvious right answer. It is worth highlighting some particular areas where primary health care ethics may need rethinking.

\section{Patient autonomy and respect for the patient as participant in health care}

Traditional provider/patient relationships within the NHS have been characterized by benevolent paternalism based on the active/passive paradigm of provider and patient. Autonomy includes at the minimum, respect for the dignity and worth of the patient regardless of competence, and respect for differing cultural, religious and social values. Respect for the patient also entails respect for privacy, including the confidentiality of patient information. This is both an ethical and a legal obligation (Human Rights Act 1998, Data Protection Act 1998).

Respect for autonomy will now also require recognition of the patient's status as a negotiator in the determination of care. Autonomy rests on genuine informed consent where patients are accorded the right to all the information necessary to make an informed choice as to treatment. English law has not as yet recognized informed consent (Sidaway v Bethlem Royal Hospital Governors [1985] 1 All ER 643), although legal developments in other comparable common law jurisdictions support patients' rights to treatment information (Rogers $v$ Whitaker (1992) 109 ALR 625).

English case-law has focused on autonomy within secondary care services and has paid little attention to the primary health care context, but one principle that has emerged from the case law is that the less urgent and necessary the medical treatment, the more important it is that the patient be informed of risks. This suggests that in primary health care there is greater obligation to accord autonomy to the patient than in secondary care, and health providers must 'consider (patient's) needs and priorities when disclosing information' (General Medical Council, 1998).

Not all practitioners have taken on board the consequence of changes in health provision philosophy, and the BMA notes that, "current awareness of the relevant ethical and legal principles relating to consent among the medical profession is largely inadequate' (British Medical Association, 2001). This is not surprising. NHS advice to practitioners on good practice is largely focused on legal protection for practitioners rather than on patient rights, and consists primarily of making sure that the practitioner uses the appropriate form to obtain written consent for the treatment that has been recommended (NHS Executive, 2003). Written consent forms are of limited benefit in primary care. While practitioner advice stresses the importance of practitioners controlling the consenting process, the Department of Health advice to patients on consent (Department of Heath, 2001e) suggests that it is the patient who makes the final decision on treatment:

Perhaps you're the kind of person who is prepared to take some risks if there is a chance of a very good outcome. On the other hand, you might rather put up with some discomfort than have treatment which carries a small risk of making things worse - even though it ought to improve your condition. Only you can know what is most important to you.

This discrepancy between practitioner and patient understanding of consent is most likely to be apparent in primary health care where the treatment is less urgent, and the patient more knowledgeable and less compliant.

Patient autonomy may rest uneasily within evidence-based practice. Sackett et al. (2000), explaining the purpose of evidence-based medicine, defines clinical expertise as 'the ability to use our clinical skills and past experience to rapidly identify each patient's unique health state and diagnosis, their individual risks and benefits of potential interventions, and their personal values and expectations.' Evidence-based practice pre- 
supposes a relationship between the active health provider and the passive patient where the health provider imposes clinical treatment in accordance with EBM. What happens when the patient tries to negotiate alternative medical treatment? The provider may be caught between the dictates of EBM and the personal service which is now fundamental to primary health care in which the patient is a partner in treatment decision making.

The ethical framework to consent needs rethinking for application to primary health care to provide guidance in situations where the practitioner has responsibility for the social as well as the biomedical causes of illness, and where the views of the patient do not conform with evidence-based solutions. At the same time primary health care ethics will need to recognize fully informed consent if the patient is to be a stakeholder in services to any meaningful extent. This imposes a positive obligation to lay all relevant facts before the patient as appropriate to the circumstances, not just a passive duty to respond to questioning. If the patient as stakeholder is to have any meaning, patients will be able to choose their own profile of health, their own health priorities, and their own health risks.

\section{Access to health services}

The factors which differentiate primary from secondary health care include ease and flexibility of access to health services, and government policy has focused on improving absolute access to care. There has been some attempt to address issues of relative access by means such as NHS Direct, but initiatives appear to have most benefited those who already use existing services and have done little to improve access to health care services to those most disadvantaged (Abbott, 2003).

Human rights law will enable challenge of disparate services particularly where there is obvious discrimination in provision of services on grounds of age, disability, social class or ethnic group. This will be particularly relevant to rationing of treatments and medicines in an environment of increased budgetary autonomy for primary health care practices. Patient demand for services may not always be refuted on economic grounds, and primary health care providers will need to find new ways of balancing patient demand and health resources. The legal obligations in the Human Rights Act reflect the ethical obligation to distribute resources in accordance with the ethical principle of distributive justice, and this principle must underpin contemporary primary health care.

More difficult is addressing issues of resource allocation in relation to health rather than health care services. Health disparities linked to social class are well documented (Smeeth, 1999). While the causes may be social and economic, there will be consequences for health which the health service cannot ignore since primary health care is no longer focused only on biological health. Responsibility for the wider 'primary' health of the patient will mean greater responsibility for eliciting patient information on social environment, recognizing the impact of social capital on patient health (Caan, 2003). This will result in greater responsibility for taking into account socioeconomic circumstances in treatment options, and may create conflict with EBM-directed solutions based on biomedical efficacy.

A further access issue arises at the interface between primary and secondary care. The UK model of primary health care continues to place the general practitioner at the gateway of access to secondary care services and medicines as a cost management measure (Coulter, 1998; Price and Williams, 2003). The demanding patient may perceive the primary health care provider as restricting or rationing patient access to secondary care resources.

This will be particularly so in the case of the expert patient who wishes to self-manage treatment. Some renegotiation may be needed to account for the cultural shift in patient/provider boundaries, with patients knowledgeable and demanding of health resources. Studies suggest that the role of the primary health care provider as a filter to access to secondary care can 'have a deleterious effect on physician-patient relationships, clinical freedom, and the overall quality of care' (Grumbach, 1999). Primary health care practice will need to operate within a well defined and understood framework in which patient autonomy is respected, but there will be times when that respect cannot translate into compliance with patient demand. In modern primary health care, the provider as filter to secondary care might prove an increasingly uncomfortable role, a role 
which will need the assistance of ethics to resolve conflicting demands.

\section{Professional boundaries}

Primary health care services take responsibility for an area of health in which the boundaries are poorly defined and often encroach on social care (Flynn et al., 1996; Goodman et al., 2003), raising questions of overlapping obligations. At the same time, the single practitioner has been replaced by group practices of multidisciplinary teams. Teamworking is well established in secondary care, where hierarchies and professional cultures have been established and strategies for dealing with conflict refined. It will take time for team-working practices to develop within primary health care. Meanwhile professionals will find themselves in a context of shifting boundaries of professional identity, creating professional uncertainty (Price and Williams, 2003) and requiring renegotiation and collaboration of provider roles.

Cultural differences between different health professions may have implications for the movement of health care work between professional groups, or may result in the breaking down of professional boundaries. Either way there will be, initially at least, professional tensions which could inhibit the expansion of primary care roles (Williams et al., 1997; Williams and Sibbald, 1999). The interprofessional nature of primary health care teams will raise new ethical issues of responsibility and accountability for patient care. Ethics guidelines issued by professional bodies have traditionally been designed for the guidance of members of individual professional groups, but ethics would provide greater support for contemporary health care practice if it focused on the job or function of practice rather than on the person who is carrying out the task.

Meanwhile in an ageing population, there have been profound shifts in caring responsibilities from the state to families (Goodman et al., 2003) at a time of reduced family size and significant family dispersal. Improved technology has enabled patients with higher dependencies and patients with serious chronic disease to be cared for within the home. District nursing services are becoming increasingly important within primary health care, with a focus across secondary health, primary health care and social care boundaries.
Similarly unpaid carers are essential to the delivery of primary health care, and carers, like patients, will become increasingly knowledgeable stakeholders demanding recognition and input into health decisions. This will have implications for professional/nonprofessional boundaries which have traditionally been clearly demarcated, and again raise issues of accountability and responsibility.

\section{Domain boundaries}

Many public health responsibilities have devolved from health authorities to primary care trusts requiring primary health care providers to consider in their decision making not just individual best interest but also the best interests of communities and local populations. This has created a new 'bottom-up' (Department of Health, 2002f) kind of public health focusing on front line health inequalities, screening and continuous first contact communicable disease control rather than wider population health and determination of public health policy. There may be conflict between both top-down and bottom-up public health responsibilities, and public health and primary health care responsibilities. Global health concerns such as ageing populations, increasing chronic illness, new epidemic disease and increasing health costs will impact most heavily on primary health services (Goodman et al., 2003; World Health Organization, 1999) and this will require resolution of difficult questions of resource allocation.

Services which have traditionally been provided within a secondary care setting will now fall within primary health care, with economic consequences for primary health care providers (Scott, 1996). Modern primary health care makes use of drug technology, taking responsibility for the administration of powerful, life-saving drugs. This means that primary health care plays an increasingly important role in reducing mortality (Gray, 2003). Much care that has traditionally been categorized as specialist and provided in the secondary sector will now fall within the domain of primary care. Increasingly primary health care providers may be required to make end of life decisions, particularly in relation to provision of expensive medicines and referral to secondary care, and these decisions must be made within a framework of ethics. 


\section{Other issues of primary health care practice}

Other aspects of primary health care will raise issues of ethics not pertinent to secondary care. The very nature of contemporary primary health care means that the relationship between patient and provider is continuing, caring, personal and sustained (Leopold et al., 1996). The responsibility of the practitioner for wider causes of health may lead to disclosure of personal and social information which increases the relationship of intimacy and trust. Some ethics theory suggests that within professional practice, 'close relations carry a moral obligation, an obligation that carries greater weight than for nonexperienced others, (and) therefore poses moral problems, especially when it is used in discussions of prioritization of health resources' (Myhrvold, 2003). Relationships of intimacy suggest the need for particular ethics guidelines to ensure that there are agreed and understood boundaries to the relationship, and that there is no question of abuse of intimacy. Issues of confidentiality will need to be addressed, more especially where the patient is being treated by healthcare teams (Toop, 1998).

The use of the placebo in treatment also raises ethics concerns, and research suggests that much greater use of placebos may take place in primary health care practice (Hróbjartsson and Norup, 2003). Issues of advertising of services of health services may become a primary health care issue since the relaxing of GMC limitations on making information available to the public (Irvine, 1991), more especially in view of the Freedom of Information Act 2003 which will require primary health care practices to publish detailed information about the practice, its services and its participants.

These issues all raise difficult ethical questions. Primary health care, like secondary care, must operate within an ethics framework.

\section{Conclusion}

Given the uncertainty surrounding change in health provision, with the constraints imposed by evidence-based medicine and human rights, an ethical framework to primary health care practice is essential. There have not yet developed common good practice guidelines to assist in hard cases - these guidelines take time to refine and need to undergo testing against both professional and legal regulation before they can be relied upon as norms of practice. Meanwhile, without an understanding of primary health care ethics, practitioners will find themselves acting in a regulatory vacuum.

There have been suggestions for building clinical ethics support into primary health care (Peile, 2001), recognizing that ethical problems will arise in the day to day work of primary health care providers. Proposals include the provision of a hotline to experienced ethics advice. However, there is an assumption that primary health care ethics comprise a branch of the more developed body of secondary care ethics, and that experience of ethics in the secondary sector can be used to provide a resource for emerging primary care ethics.

It is no longer the case that primary health care can be regarded as subsidiary to secondary care, such that what works for secondary care can be adapted for primary health care. It is no longer the case that serious ethical dilemmas arise primarily in the secondary sector; much acute illness will present at the first instance in a primary health care environment. Extrapolating from codes of secondary care ethics may prove confusing and misleading to the primary care provider. An ethical framework devoted to the particular needs of primary health care practitioners, especially in an era of change, will be essential to the implementation of an effective modern primary health care system.

\section{References}

Abbott, S. 2003: Equity of access to primary care in the UK: is it likely to increase? Primary Health Care Research and Development 4, 187-89.

British Medical Association. 2001: Report of the consent working party: incorporating consent toolkit. London: British Medical Association.

Caan, W. 2003: Public health networks and primary care trusts. Primary Care Research and Development 4, 1-3.

Commission on the Future of Health Care in Canada. 2002: Building on values: the future of health care in Canada. Saskatoon

Coulter, A. 1998: Managing demand at the interface between primary and secondary care. British Medical Journal 316, 1974-76. 
Brooks, F. 2001: Why user involvement in primary care? In Gillam, S and Brooks, F. editors, New beginnings: towards patient and public involvement in primary health care. King's Fund: University of Luton.

Davis, A. 1997: Selected ethical issues in planned social change and primary health care. Nursing Ethics 4 (3) 239.

Department of Health. 1996: The patient's charter and you: a charter for England. London: HMSO.

Department of Health. 1997: The new NHS - modern, dependable. London: HMSO.

Department of Health. 2001a: Shifting the balance of power within the NHS. London: HMSO.

Department of Health. 2001b: Modernising the NHS: shifting the balance of power in London. London: HMSO.

Department of Health. 2001c: Primary care, general practice and the NHS plan. London: HMSO.

Department of Health. 2001d: The expert patient: a new approach to chronic disease management for the 21st century. London: HMSO.

Department of Health. 2001e: Consent - what you have a right to expect. A guide for adults. London: HMSO.

Department of Health. 2002a: Delivering the NHS plan. London: HMSO.

Department of Health. 2002b: Health improvement and prevention: a practical aid to implementation in primary care. London: HMSO.

Department of Health. 2002c: National service frameworks: a practical aid to implementation in primary care. London: HMSO.

Department of Health. 2002d: Achieving and sustaining improved access to primary care. London: HMSO.

Department of Health. 2002e: Delivering the NHS plan: next steps on investment, next steps on reform. London: HMSO.

Department of Health. 2002f: Shifting the balance of power: the next steps. Appendix C. Public health. London: HMSO.

Department of Health. 2003a: Liberating the talents. Helping primary care trusts and nurses to deliver the NHS plan. London: HMSO.

Department of Health. 2003b: Strengthening accountability: involving patients and the public. Practice guidance. London: HMSO.

Department of Health. 2003c: Overview and scrutiny of health: Guidance. London: HMSO.

Dorrell, S. 1996: Primary care the future. Leeds: Department of Health.

Flynn, R., Pickard, S. and Williams, G. 1996: Markets and networks: contracting in community health services. Buckingham: Open University Press.

General Medical Council. 1998: Seeking patients' consent: the ethical considerations. London: General Medical Council.

Goodman, C., Ross, F., MacKenzie, A. and Vernon, S. 2003: A portrait of district nursing: its contribution to primary health care. Journal of Interprofessional Care 17 (1), 97-108.

Goodman, K.W. 2003: Ethics and evidence-based medicine. Cambridge: Cambridge University Press.
Gray, D.P. 2003: Role reversal between primary and secondary care. Medical Education 37, 754-55.

Grumbach, K. 1999: Primary care in the United States - the best of times, the worst of times. New England Journal of Medicine 341, 2008-10.

Grahame-Smith, D. 1995: Evidence based medicine: Socratic dissent. British Medical Journal 310, 1126-27.

Greenhalgh, T., Toon, P., Russell, J., Wong, G., Plumb, L. and Macfarlane, F. 2003: Transferability of principles of evidence based medicine to improve educational quality: systematic review and case study of an on-line course in health care. British Medical Journal 326, 142-45.

Hammersley, M. 2001: On 'systematic' reviews of research literatures: a 'narrative' response to Evans and Benefield. British Educational Research Journal 27 (5), 543-54.

Hróbjartsson, A. and Norup, M. 2003: The use of placebo interventions in medical practice - a national questionnaire survey of Danish clinicians. Evaluation and the Health Professions 26 (2), 153-65.

Irvine, D. 1991: The advertising of doctors' services. Journal of Medical Ethics 17 (1), 35-40.

Leopold, N., Cooper, J. and Clancy, C. 1996: Sustained partnership in primary care. Journal of Family Practice 42, 129-37.

Loughlin, M. 2003: Essay review: ethics and evidence-based medicine: fallibility and responsibility in clinical science. Journal of Evaluation in Clinical Practice 9, 141-44.

Malterud, K. 2001: The art and science of clinical knowledge: evidence beyond measures and numbers. Lancet 358, 397-400.

Myhrvold, T. 2003: The exclusion of the other: challenges to the ethics of closeness. Nursing Philosophy 4, 33-43.

Milburn, A. 2002: Devolution day for the NHS. London: Department of Health, 1 April.

NHS Executive. 2003: Health service circular: good practice in consent. (revised 2001 circular). London: NHS Executive.

Peile, E. 2001: Supporting primary care with ethics advice and education. British Medical Journal 323, 3-4.

Price, A. and Williams, A. 2003: Primary care nurse practitioners and the interface with secondary care: a qualitative study of referral practice. Journal of Interprofessional Care 17 (3), 239-50.

Pringle, M. 1997: Primary care: opportunities and threats: distributing primary care fairly. British Medical Journal 314, 595.

Quah, S. 2003: Traditional healing systems and the ethos of science. Social Science and Medicine 57, 1997-2012.

Reeves, C. (Director of Finance and Performance) 2001: Extra resources for 2000/2001: access and enhanced services for primary care. London: Department of Health.

Royal College of General Practitioners. 2003: GPnotebook at www.gpnotebook.co.uk

Sackett, D., Rosenberg, W., Gray, J., Haynes, B. and Richardson, W. 1996: Evidence based medicine: what it is and what it isn't. British Medical Journal 312, 71-72.

Sackett, D., Straus, S., Richardson, W., Rosenberg W. and Haynes, R. 2000: Evidence based medicine: how to practise and teach EBM. Edinburgh: Churchill Livingston. 
Scott, A. 1996: Primary or secondary care? What can economics contribute to evaluation at the interface? Journal of Public Health Medicine 18, 19-26.

Secretary of State for Health in England. 1996: Primary care: delivering the future. London: HMSO.

Sehon, S. and Stanley, D. 2003: A philosophical analysis of the evidence-based medicine debate. BMC Health Services Research 3, 14-24.

Smeeth, L. 1999: Tackling health inequalities in primary care. British Medical Journal 318, 1020-21.

Tang, K., Ehsani, J. and McQueen, D. 2003: Evidence based health promotion: recollections, reflections and reconsiderations. Journal of Epidemiology and Community Health 57, $841-43$.
Toop, L. 1998: Primary care: core values. Patient centred primary care. British Medical Journal 316, 1882-83.

Williams, A., Robins, T. and Sibbald, B. 1997: Cultural differences between medicine and nursing: implications for primary care. Manchester: National Primary Care Research and Development Centre.

Williams, A. and Sibbald, B. 1999: Changing roles and identities in primary health care: exploring a culture of uncertainty. Journal of Advanced Nursing 29, 737-45.

World Health Organization. 1999: Health 21: an introduction to the health for all policy framework for the WHO european region. Copenhagen: WHO.

World Health Organization. 2003: Primary health care: a framework for future strategic directions (updated draft). Geneva: WHO. 